\title{
COMUNICAÇÃO
}

\section{CARACTERÍSTICAS VISUAIS DA EMBALAGEM DE CAFÉ NO PROCESSO DE DECISÃO DE COMPRA PELO CONSUMIDOR ${ }^{1}$}

\author{
Visual characteristics of coffee package on consumer's purchase decision process
}

\author{
Suzana Maria Della Lucia², Valéria Paula Rodrigues Minim, Luis Antonio Minim4, Carlos Henrique Osório Silva
}

\section{RESUMO}

Conduziu-se este trabalho, com o objetivo de investigar, usando grupos de foco, atitudes, opiniões, conceitos e pensamentos de consumidores sobre embalagens de café torrado e moído que refletem na sua decisão de compra. Três sessões de grupo de foco de 90 minutos foram realizadas (duas em Viçosa/MG e uma em Londrina/PR), num total de 24 participantes. Foram apresentadas cinco embalagens de café (sendo quatro orgânicas, em razão da maior preocupação em obter dados sobre café orgânico) para estimular a conversação, sendo seguido um roteiro de perguntas. Os dados obtidos foram estudados, considerando palavras utilizadas pelos consumidores, sem análise estatística, em razão da característica qualitativa de grupos de foco. Foi observado que os principais fatores considerados no processo de decisão de compra são: preço, cor da embalagem e marca. Muitos participantes mostraram-se fiéis a marcas e outros admitiram pagar mais por um produto orgânico, dependendo do preço do mesmo. Foi sugerido que na embalagem de café orgânico deveria ser salientada a definição do produto para aqueles que não conhecem tal técnica de produção.

Termos para indexação: Café orgânico, grupo de foco, comportamento, método qualitativo.

\begin{abstract}
Focused group technique was used in this work with the aim of investigating consumers' attitudes, opinions, concepts and thoughts related to coffee package, which may affect their purchase decision. Three focus group sessions of ninety minutes were carried out (two sessions in Viçosa/MG and one session in Londrina/PR), totaling 24 participants. Five coffee packages were presented (four being organic coffee packages due to the necessity of obtaining more information about organic coffee). In order to stimulate discussion all consumers (participants?) were asked to fill in a questionnaire after each session. The obtained data were studied taking into account statements made by consumers without performing any data statistical analysis due to the focused group's qualitative nature. The main observed factors presented on coffee package during the purchase process were price, package color and brand. Many consumers were loyal to brand and others admitted to pay more for an organic product, depending on its price. It is suggested that on the organic coffee package labeling should be emphasized the product identification for those who don't know anything about organic production technique.
\end{abstract}

Index terms: Organic coffee, focused group, behavior, qualitative method.

\section{(Recebido em 22 de fevereiro de 2007 e aprovado em 3 de junho de 2008)}

O Brasil é o país que apresenta a maior produção mundial de café convencional, sendo também o maior exportador, gerando uma receita anual de aproximadamente 3 bilhões de dólares (EMBRAPA, 2007). Em relação à produção de café orgânico, observa-se que esta tem aumentado a cada ano no Brasil, sendo um reflexo do aumento da demanda mundial por alimentos orgânicos, considerados de qualidade e saudáveis.

A demanda no mercado interno por cafés diferenciados (como o orgânico) ainda é baixa, o que pode se agravar pelo seu preço de mercado ser em média $40 \%$ mais valorizado do que o do produto convencional (INFORMATIVO CAFÉ, 2007), o que se alia à baixa renda média da população. Não se pode negar, entretanto, que o mercado interno tem grande potencial para o consumo de cafés diferenciados AGUIAR-MENEZES et al., 2008). O decréscimo de confiança na qualidade de alimentos convencionais e o aumento da preocupação com a saúde são fatores que levam ao consumo de alimentos orgânicos (SILVA et al., 2009), inclusive do café orgânico.

\footnotetext{
${ }^{1}$ Parte do trabalho de dissertação de Mestrado do primeiro autor.

${ }^{2}$ Engenheira de Alimentos, Doutora em Ciência e Tecnologia de Alimentos, Professora - Centro de Ciências Agrárias/CCA - Departamento de Engenharia Rural/ERU - Universidade Federal do Espírito Santo/UFES - Alto Universitário, s/n - Guararema - Cx. P. 16 - 29500-000 - Alegre, ES - sdlucia@cca.ufes.br ${ }^{3}$ Engenheira de Alimentos, Doutora em Ciência de Alimentos, Professora - Departamento de Tecnologia de Alimentos/DTA - Universidade Federal de Viçosa/UFV - Avenida P.H. Rolfs, s/n - Centro - 36570-000 - Viçosa, MG - vprm@ufv.br

${ }^{4}$ Engenheiro de Alimentos, Doutor em Engenharia Química, Professor - Departamento de Tecnologia de Alimentos/DTA - Universidade Federal de Viçosa/UFV - Avenida P.H. Rolfs, s/n - Centro - 36570-000 - Viçosa, MG - Iminim@ufv.br

${ }^{5}$ Engenheiro Agrônomo, Doutor em Estatística, Professor - Departamento de Informática/DPI - Universidade Federal de Viçosa/UFV - Avenida P.H. Rolfs, s/n - Centro - 36570-000 - Viçosa, MG - chos@dpi.ufv.br
} 
Mesmo com tamanha importância para o mercado brasileiro, pouco se conhece sobre as preferências do consumidor em relação à bebida de café orgânico ou convencional (MONTEIRO, 2002), tampouco sobre sua aceitação ou sobre os fatores que levam um indivíduo a escolher e a comprar tal produto.

Não há dúvida de que a relação entre o consumidor e a escolha, a compra e, especialmente, a aceitação de um produto é um fenômeno bastante complexo. A atitude do consumidor é influenciada por fatores relacionados à psicologia que envolve o indivíduo, ao aspecto sensorial do produto e ao marketing relacionado a ele (GUERRERO et al., 2000). Dessa forma, a otimização da aceitação de um produto requer não apenas a identificação de propriedades sensoriais consideradas importantes para o consumidor, mas também de várias características externas, que podem aumentar ou diminuir o consumo do produto (DANTAS et al., 2004). Atributos como o rótulo e seu conteúdo (marca, preço, informação) podem gerar expectativa e alterar sua percepção (DELIZA et al., 2003).

Uma vez que o comportamento do consumidor é multidisciplinar, o uso de pesquisas qualitativas tem gerado resultados interessantes sobre a percepção do produto, assim como sua aceitação ou rejeição, uma vez que elas permitem a obtenção de informações detalhadas sobre atitudes, opiniões, comportamentos e hábitos dos participantes (HASHIM et al., 1996). Uma técnica qualitativa de levantamento de dados empregada para esse tipo de estudo é denominada grupo de foco, definida como um meio de entrevista cuidadosamente planejado, com o intuito de obter opiniões individuais de pessoas de um grupo sobre determinada área de interesse. É uma sessão conduzida com seis a nove pessoas, por um moderador imparcial que permita que o grupo expresse sua opinião sobre o assunto livremente, explorando ao máximo o tema em debate (CASEY \& KRUEGER, 1994). Como todo método de pesquisa, o grupo de foco apresenta vantagens e desvantagens. Como vantagens, essa técnica provê informações difíceis de serem obtidas por outros métodos, uma vez que sua dinâmica encoraja os participantes a mostrar suas atitudes (NGAPO et al., 2003). Os participantes respondem as questões com suas próprias palavras, o que garante maior liberdade de expressão; além disso, o método permite fácil entendimento da técnica e leva a resultados confiáveis (DRANSFIELD et al., 2004). Como limitações, Casey \& Krueger (1994) citam a dificuldade na análise dos dados (difícil interpretação das idéias dos participantes), além da necessidade de um moderador bem treinado, que tenha experiência e conhecimento para evitar que a sessão seja dominada por apenas alguns participantes mais extrovertidos.

Em razão do caráter exploratório que possui, as sessões de grupo de foco são bastante aplicadas quando pouco se conhece sobre o objeto em estudo (BÄCKSTRÖM et al., 2003; DELIZA et al., 2003). São utilizadas em diversas áreas, como a medicina, a nutrição, o marketing, a educação da saúde, a área social, a política e são bastante empregadas em estudos de ciência e tecnologia de alimentos (DELIZA et al., 2003; DI MONACO et al., 2004; DRANSFIELD et al., 2003; NGAPO et al., 2003). As sessões de grupo de foco têm sido empregadas, inclusive, como uma etapa preliminar em pesquisas que precisam obter informações sobre a atitude, a opinião e o comportamento dos participantes frente a determinado assunto (GUERRERO et al., 2000). Nesse contexto, vários trabalhos foram desenvolvidos em ciência de alimentos para estudar as características relevantes das embalagens e rótulos de produtos sobre a escolha dos consumidores, tendo grupos de foco como etapa preliminar (CARNEIRO, 2002; COSTA, 1999; REIS, 2007; SOUZA et al., 2004).

Como parte do estudo do impacto da embalagem de café orgânico na intenção de compra do consumidor, a técnica "grupo de foco" foi aplicada para investigar atitudes, opiniões, conceitos e pensamentos dos consumidores sobre a embalagem de café torrado e moído. Além disso, foi usada para identificar os fatores mais relevantes da embalagem quando do processo de escolha do produto.

Três sessões de grupo de foco, com um total de 24 consumidores foram conduzidas, sendo duas realizadas em Viçosa, Minas Gerais, e uma em Londrina, Paraná. A primeira sessão contou com seis participantes (cinco mulheres e um homem) e a segunda com oito (quatro mulheres e quatro homens), realizadas em Viçosa, Minas Gerais. A terceira sessão foi composta por dez pessoas (sete mulheres e três homens), sendo realizada em Londrina, Paraná. Os participantes foram selecionados por meio de questionários de recrutamento, sendo a seleção feita a partir das respostas obtidas para questões envolvendo consumo de café, hábito de freqüentar supermercado e de ler o rótulo de produtos. Assim, todos os participantes freqüentavam supermercados e consumiam café regularmente. Os consumidores eram voluntários, não recebendo incentivo monetário para sua participação no estudo.

As sessões ocorreram em sala com mesa oval, contando com um moderador e um assistente (encarregado de gravar e anotar cada sessão). O moderador explicou o propósito da sessão e esclareceu sobre a importância da 
opinião de cada participante no estudo, prosseguindo com a utilização de um roteiro de perguntas (Tabela 1) sobre o hábito dos consumidores durante suas compras. As questões do roteiro foram, também, relacionadas às cinco embalagens de café apresentadas aos consumidores. Foi ressaltado aos participantes que não existia resposta correta para as questões abordadas, sendo importante apenas a opinião de cada indivíduo. Cada sessão teve duração média de 90 minutos.

Tabela 1 - Roteiro para as sessões de grupo de foco.

\begin{tabular}{cl}
\hline Pergunta & \multicolumn{1}{c}{ Descrição } \\
\hline 1 & $\begin{array}{l}\text { Você observa os rótulos dos produtos que } \\
\text { consome? }\end{array}$ \\
\hline 2 & O que você observa? \\
\hline 3 & O que mais chama sua atenção? \\
\hline 4 & O que você achou destas embalagens? \\
\hline 5 & $\begin{array}{l}\text { O que você considera importante nestas } \\
\text { embalagens? }\end{array}$ \\
\hline 6 & $\begin{array}{l}\text { Você gostaria de ver alguma outra } \\
\text { informação no rótulo? }\end{array}$ \\
\hline 7 & $\begin{array}{l}\text { Como você entende a expressão: 'produto } \\
\text { orgânico'? }\end{array}$ \\
\hline 9 & $\begin{array}{l}\text { Como dizer, no rótulo, que o produto é } \\
\text { orgânico? }\end{array}$ \\
\hline 10 & $\begin{array}{l}\text { Se estivesse no rótulo a informação: } \\
\text { "produto orgânico", você compraria? }\end{array}$ \\
\hline 11 & $\begin{array}{l}\text { Você pagaria mais por este produto? } \\
\text { O que você acha das informações 'produto de agrotóxicos"' e "sem agrotóxicos, } \\
\text { aditivos ou conservantes"'? }\end{array}$ \\
\hline
\end{tabular}

As embalagens empregadas nas sessões foram escolhidas para serem apresentadas aos participantes em razão da sua diversificação em termos de cor, marca e informações, a fim de prover elementos para discussões mais ricas, assim como em estudo de Dantas et al. (2004). Elas eram, em sua maioria, desconhecidas pelos participantes. No Tabela 2, estão descritas as características das embalagens de café utilizadas nas sessões, enfatizando as informações contidas nas mesmas. Das cinco embalagens usadas, quatro eram de café orgânico e apenas uma de café convencional. A opção por empregar maior quantidade do produto do tipo orgânico deu-se em razão de ser este trabalho uma etapa inicial no estudo do comportamento do consumidor de café orgânico, e por esta razão houve uma preocupação maior em obter dados acerca deste tipo de produto.
Todos os dados obtidos por meio dos questionários dos consumidores, das gravações e das anotações das respostas foram lidos e estudados, considerando as palavras utilizadas pelos participantes, a presença de afirmativas ou idéias semelhantes, o contexto da pergunta e a especificidade das respostas, sem o emprego de análise estatística, em razão da característica qualitativa do estudo. As percepções diferentes ou divergentes entre os participantes também foram comentadas. Os resultados foram descritos da maneira como haviam sido obtidos nas sessões, de modo a não perder a autenticidade das idéias apresentadas. Utilizaram-se valores percentuais para facilitar o entendimento das respostas (DANTAS et al., 2004).

Os dados demográficos dos consumidores são apresentados na Tabela 3. A faixa etária predominante foi de 20 a 29 anos $(41,7 \%)$; 66,7\% dos participantes eram do sexo feminino. Dos 24 participantes, $71 \%$ possuíam pósgraduação e $37,5 \%$ disseram ter renda familiar mensal de um a cinco salários mínimos.

Dos 24 consumidores, $41,7 \%$ (dez pessoas) sempre lêem rótulos dos produtos que consomem, $37,5 \%$ (nove pessoas) lêem frequientemente e 20,8\% (cinco pessoas) afirmaram ler, às vezes, os rótulos das embalagens.

Os consumidores informaram no questionário aplicado que as principais características da embalagem observadas no momento da compra são: prazo de validade, marca, informações sobre ingredientes e preço. Carneiro (2002), Dantas et al. (2004) e Reis (2007) também observaram em seus estudos que o preço, a marca e a data de validade são de grande importância na decisão de compra. As sessões de grupo de foco realizadas também indicaram que o preço $(75 \%)$, a marca $(83,3 \%)$ e a cor da embalagem (75\%) são as características que mais interferem na intenção de compra dos consumidores. Muitos participantes mostraram-se fiéis a marcas tradicionais, algumas vezes evitando a compra de produtos de marca desconhecida. Esta observação é consistente com a hipótese de que marcas conhecidas ou estabelecidas no mercado geram a expectativa de um produto de qualidade (JAEGER, 2006), ainda que o mesmo seja desconhecido.

Em relação ao preço, afirmativas como "só pagaria mais por um produto orgânico se a diferença de preço fosse de até $30 \%$ a mais do que costumo pagar" foi bastante comum durante as sessões. Dantas et al. (2004) observou a mesma tendência nas respostas dos consumidores quanto ao fator preço, para produtos minimamente processados. Em um estudo de Reis (2007), foi constatado que um dos principais fatores que os consumidores levam em consideração quando compram iogurte light é o preço. 
Tabela 2 - Descrição dos produtos utilizados neste estudo.

\begin{tabular}{cl}
\hline Produto & \multicolumn{1}{c}{ Descrição } \\
\hline & Café marca A em embalagem flexível, rótulo preto/verde escuro, ilustrações de xícara de café, \\
pequenos animais (borboleta, tucano, macaco) e globo terrestre. Informações no painel frontal, em \\
dourado: orgânico, marca, café orgânico, torrado e moído, vácuo puro (nos idiomas português e \\
inglês), peso líquido 250 g (net wt. $8.8 \mathrm{oz}$ ) e indústria brasileira; em cor branca, os dizeres: absoluto, \\
produto livre de agrotóxicos. \\
Café marca B em embalagem metalizada, rótulo branco listrado de verde e ilustração de sol, xícara de \\
café, grãos e plantação de café, árvores e folhas verdes. Informaçóes no painel frontal, nas cores \\
verde, branca, preta ou vermelha: marca, café orgânico, sem agrotóxicos, aditivos ou conservantes, \\
prazer de viver light, grãos selecionados, torrados e moídos, vácuo puro, linha orgânica, peso líquido \\
250 g e indústria brasileira; selo de pureza ABIC*. \\
Café marca C em embalagem de papel, rótulo nas cores verde, laranja, vermelho e preto e ilustração \\
de xícara de café. No painel frontal, as informações nas cores preta ou branca: café superior \\
qualidade, marca, seleção 100\% qualidade, aralto com grãos cultivados em altitudes superiores a 1000 \\
m, orgânico, indústria brasileira, peso líquido 250 g, café torrado e moído orgânico; símbolo do selo \\
de qualidade IBD/IFOAM**. \\
Café marca D em embalagem cartonada, rótulo verde escuro. Ilustração de xícara de café branca e \\
grãos de café na cor marrom. Painel frontal com as informações nas cores branca, preta ou dourada: o \\
café feito pra você, marca, gourmet orgânico, o sabor do puro café 100\% natural, indústria brasileira, \\
alto vácuo, peso líq. 250 g, café torrado e moído, 100\% arábica.
\end{tabular}

* ABIC: Associação Brasileira da Indústria de Café

** IBD: Instituto Biodinâmico; IFOAM: International Federation of Organic Agriculture Movements

Tabela 3 - Características demográficas dos 24 participantes das sessões de grupo de foco

\begin{tabular}{lcc}
\hline Característica & Descrição & Frequência $(\%)$ \\
\hline Sexo & Masculino & 33,3 \\
Idade (anos) & Feminino & 66,7 \\
& $20-29$ & 41,7 \\
& $30-39$ & 12,5 \\
Grau de instrução & $40-49$ & 33,3 \\
& $50-59$ & 12,5 \\
& 2 grau & 8,3 \\
Renda & Superior incompleto & 8,3 \\
(salários mínimos) & Superior completo & 12,5 \\
& Pós-graduação & 71,0 \\
& 1 a 5 & 37,5 \\
& 6 a 10 & 16,7 \\
\hline
\end{tabular}


Entretanto, no presente estudo, alguns consumidores pareciam dispostos a pagar mais por um produto diferenciado $(20,8 \%$ do total), o que pode refletir na presença de participantes de renda familiar mensal superior a 20 salários mínimos. Além disso, o crescimento da preocupação com o ambiente e com o consumo de alimentos mais seguros também pareceu ser um fator de favorecimento à procura pelo café orgânico, de preço superior ao convencional, fato também observado por Bressan et al. (2007) e Hearty et al. (2007). Alvensleben \& Altman (1987) observaram que o consumo de alimentos orgânicos é relacionado à diminuição da confiança na qualidade de alimentos convencionais e num aumento da preocupação com a saúde, o que reafirma as respostas encontradas com o estudo com os consumidores de café.

As respostas obtidas para cada produto durante as sessões estão resumidas no Tabela 4.

É interessante ressaltar que grande parte dos consumidores (um total de 75\%) informou preferir cores marrons e avermelhadas para a embalagem de café, alegando que "a cor para café é marrom com vermelho". Foi levantada a possibilidade por alguns consumidores $(37,5 \%)$ de a cor verde estar sendo associada ao produto orgânico, uma vez que todos os rótulos das embalagens de café orgânico traziam tal cor, ao menos em alguns detalhes. Três participantes (12,5\% do total) recomendaram que todo rótulo de café deveria trazer especificado o tipo de torra utilizada na obtenção do produto. A procedência também pareceu ser de interesse de alguns consumidores (16,7\% dos participantes), que prezam o local de produção. Foi cogitado por um participante o uso de embalagens de aparência mais rústica para o produto orgânico, as quais estariam mais bem identificadas com tal tipo de produto.

No que diz respeito à definição de "produto orgânico", apenas dois participantes declararam não saber o significado de tal termo; vale ressaltar que a maioria dos consumidores possuía pós-graduação e alguns estavam relacionados à área de ciência e tecnologia de alimentos, o que talvez facilitasse o entendimento do termo; foi sugerido que se especificasse nas embalagens o sentido da

Tabela 4 - Resumo das respostas mais freqüentes nas sessões de grupo de foco

\begin{tabular}{|c|c|c|c|c|c|}
\hline & Produto 1 & Produto 2 & Produto 3 & Produto 4 & Produto 5 \\
\hline $\begin{array}{c}\text { Cor da } \\
\text { embalagem }\end{array}$ & $\begin{array}{l}\text { As cores são } \\
\text { muito escuras e } \\
\text { pesadas, pouco } \\
\text { atrativas. }\end{array}$ & $\begin{array}{l}\text { A cor clara me } \\
\text { agradou, mas o } \\
\text { contraste de } \\
\text { cores no rótulo } \\
\text { não é bom. }\end{array}$ & $\begin{array}{l}\text { As cores são } \\
\text { muito alegres, } \\
\text { chamativas; a } \\
\text { mistura de cores } \\
\text { me agradou. }\end{array}$ & $\begin{array}{l}\text { O verde parece ser } \\
\text { relacionado ao } \\
\text { orgânico, mas } \\
\text { ainda prefiro cores } \\
\text { amarronzadas. }\end{array}$ & $\begin{array}{c}\text { A cor da } \\
\text { embalagem pode } \\
\text { até ser atrativa, mas } \\
\text { é muito escura. }\end{array}$ \\
\hline Preço & $\begin{array}{l}\text { Não pagaria } \\
\text { mais por ela, só } \\
\text { se fosse até } \\
20 \% \text { mais cara. }\end{array}$ & $\begin{array}{l}\text { Eu não pagaria } \\
\text { mais por ela. }\end{array}$ & $\begin{array}{l}\text { Até pagaria mais } \\
\text { por ela, } \\
\text { dependendo do } \\
\text { preço. }\end{array}$ & $\begin{array}{l}\text { Apesar de ser } \\
\text { sofisticada, dá } \\
\text { impressão de ser } \\
\text { mais cara e não } \\
\text { pagaria mais } \\
\text { por ela. }\end{array}$ & $\begin{array}{l}\text { Não pagaria mais } \\
\text { pela embalagem } \\
\text { mais cara. }\end{array}$ \\
\hline Informações & $\begin{array}{l}\text { Os dizeres } \\
\text { “orgânico" e } \\
\text { "produto livre } \\
\text { de agrotóxicos" } \\
\text { deveriam ter } \\
\text { mais destaque. }\end{array}$ & $\begin{array}{l}\text { A embalagem é } \\
\text { "poluída" em } \\
\text { informações; } \\
\text { "prazer de viver } \\
\text { light" associa o } \\
\text { café a dieta; } \\
\text { "sem } \\
\text { agrotóxicos" } \\
\text { deveria ser mais } \\
\text { explorado. }\end{array}$ & $\begin{array}{l}\text { Informações } \\
\text { sobre orgânicos } \\
\text { são mais bem } \\
\text { explicadas; achei } \\
\text { que destacaram } \\
\text { mais o termo } \\
\text { "aralto" que o } \\
\text { termo } \\
\text { "orgânico". }\end{array}$ & $\begin{array}{c}\text { A embalagem } \\
\text { chamou atenção } \\
\text { para o orgânico, } \\
\text { mas não explicou } \\
\text { o que é; o selo } \\
\text { deveria ter lugar } \\
\text { de destaque no } \\
\text { painel frontal; o } \\
\text { tamanho da fonte é } \\
\text { pequeno. }\end{array}$ & $\begin{array}{l}\text { O tamanho da fonte } \\
\text { é pequeno e há } \\
\text { muita informação } \\
\text { na caixa como um } \\
\text { todo. }\end{array}$ \\
\hline Marca & $\begin{array}{c}\text { A marca } \\
\text { aparece mais do } \\
\text { que a definição } \\
\text { de orgânico; } \\
\text { desconhecida. }\end{array}$ & $\begin{array}{l}\text { Marca difícil de } \\
\text { ser percebida; } \\
\text { não gostei de sua } \\
\text { associação com o } \\
\text { termo em inglês. }\end{array}$ & $\begin{array}{l}\text { Nome da marca } \\
\text { parece associado } \\
\text { a qualidade; } \\
\text { influencia na } \\
\text { compra. }\end{array}$ & $\begin{array}{l}\text { Marca conhecida; } \\
\text { influencia na } \\
\text { compra pela } \\
\text { familiaridade. }\end{array}$ & $\begin{array}{l}\text { Marca conhecida, } \\
\text { influencia na } \\
\text { compra do produto. }\end{array}$ \\
\hline
\end{tabular}


expressão "orgânico", por meio de termos como "livre de agrotóxicos, economicamente sustentável", a fim de esclarecer aos consumidores o tipo de produto contido na embalagem. A presença de informações nos rótulos dos produtos alimentícios parece ser fator decisivo para sua percepção, compra e aceitação, como foi sugerido em pesquisas anteriores (DANTAS et al., 2004; DELIZA et al., 2003; TUORILA et al., 1998). Alguns estudos demonstraram que a aceitação é maior para alimentos com os quais o consumidor está familiarizado do que para os novos (KAHKONEN et al., 1996, PELCHAT, 2000), e este fato pode ser minimizado com o fornecimento de informações acerca do produto (LAUREATI et al., 2006). Esta questão reforça o fato de que a informação é, entre os fatores que aumentam a aceitação de alimentos com os quais o consumidor não está familiarizado, a principal fonte de influência (CAPORALE et al., 2006). Segundo Tuorila et al. (1998), a expectativa do consumidor é originada pelo conhecimento prévio do produto e por informações sobre ele, razão pela qual é grande a importância das informações contidas nas embalagens.

Dois dos três grupos argüidos (58,3\% do total de participantes) entendiam a definição de "orgânico" e acreditavam na sua política de produção, mas declararam não consumir tais produtos, provavelmente por terem, em sua maioria, renda mensal de um a cinco salários. "Minha situação financeira não permite o consumo" era a explicação utilizada. Um ponto importante é que um dos grupos, apesar de conhecer a técnica orgânica de produção, afirmou quase em totalidade $(37,5 \%$ do total) que não pagaria a mais pelo produto, a despeito da renda familiar mensal do grupo ser, em sua maioria, acima de 20 salários mínimos; os consumidores afirmaram não confiar na produção e nem no selo de garantia e que só consumiriam o produto se recebessem boas referências sobre ele.

Como conclusões, observou-se que o preço, a cor da embalagem e a marca são fatores importantes no processo de decisão de compra do café. Percebeu-se, no que diz respeito às embalagens estudadas, que os consumidores não pagariam mais pelo café orgânico, a não ser que a diferença de preço não ultrapassasse de $30 \%$ entre o orgânico e o convencional. Para eles, a cor da embalagem de café deveria variar de marrom a avermelhada, o que teria mais relação com o produto. Na embalagem de café orgânico deveria ser salientada, também, a definição do produto, para que aqueles que não conhecem a técnica orgânica pudessem compreender seu significado.

Ressalta-se, aqui, a importância deste trabalho como uma etapa preliminar do estudo da intenção de compra de embalagem de café orgânico. A partir das sessões de grupo de foco, podem-se observar quais fatores da embalagem são ou parecem ser determinantes no processo de escolha pelo consumidor. Além disso, vale enfatizar a importância da realização deste tipo de pesquisa no momento anterior ao desenvolvimento do produto, uma vez que entender os fatores que levam o consumidor a escolher determinado produto possibilita à indústria desenvolver, inovar e definir estratégias de marketing para o mesmo.

\section{REFERÊNCIAS BIBLIOGRÁFICAS}

AGUIAR-MENEZES, E. de L.; SANTOS, C. M. A. dos; RESENDE, A. L. S.; LEAL, M. R.; MENEZES, E. B.

Parasitóides associados às moscas-das-frutas (Diptera: Tephritoidea) em café orgânico com e sem arborização em Valença, RJ, Brasil. Revista Ciência e

Agrotecnologia, v.32, n.6, p.1824-1831, nov./dez., 2008.

ALVENSLEBEN, R. von; ALTMANN, M. Determinants of the demand for organic foods in Germany. Acta Horticulturae, Amsterdam, v. 203, p. 235-242, 1987.

BÄCKSTRÖM, A.; PIRTTILÄ-BACKMAN, A. M.; TUORILA, H. Dimensions of novelty: a social representation approach to new foods. Appetite, v. 40, n. 3, p. 299-307, 2003.

BRESSAN, M. C.; LODI, F.; FERREIRA, M. W.; ANDRADE, P. L.; BOARI, C. A.; PICCOLI, R. H. Influência da embalagem na vida útil de presuntos fatiados. Revista Ciência e Agrotecnologia, v.31, n.2, p.433-438, mar./abr., 2007.

CAPORALE, G.; POLICASTRO, S.; CARLUCCI, A.; MONTELEONE, E. Consumer expectations for sensory properties in virgin olive oils. Food Quality and Preference, v. 17, n. 1/2, p. 116-125, 2006.

CARNEIRO, J. D. S. Impacto da embalagem de óleo de soja na intenção de compra do consumidor via conjoint analysis. 2002. 74 f. Dissertação (Mestrado em Ciência e Tecnologia de Alimentos) - Universidade Federal de Viçosa, Viçosa, 2002.

CASEY, M. A.; KRUEGER, R. A. Focus group interviewing. In: MacFIE, H. J. H.; THOMSON, D. M. H. (Eds.). Measurement of food preferences. Glasgow: Blackie Academic \& Professional, 1994. p. 77-96.

COSTA, M. C. Tecnologias não convencionais e o impacto no comportamento do consumidor. 1999. $119 \mathrm{f}$. Dissertação (Mestrado em Ciência e Tecnologia de Alimentos) - Universidade Federal Rural do Rio de Janeiro, Rio de Janeiro, 1999. 
DANTAS, M. I. S.; MINIM, V. P. R.; DELIZA, R.; PUSCHMANN, R. The effect of packaging on the perception of minimally processed products. Journal of International Food \& Agribusiness Marketing, v. 16, n. 2, p. 71-83, 2004.

DELIZA, R.; ROSENTHAL, A.; SILVA, A. L. S. Consumer attitude towards information on non-conventional technology. Trends in Food Science \& Technology, v. 14, n. 1/2, p. 43-49, 2003.

DI MONACO, R.; CAVELLA, S.; DI MARZO, S.; MASI, $P$. The effect of expectations generated by brand name on the acceptability of dried semolina pasta. Food Quality and Preference, v. 15, n. 5, p. 429-437, 2004.

DRANSFIELD, E.; MORROT, G.; MARTIN, J. F.; NGAPO, T. M. The application of a text clustering statistical analysis to aid the interpretation of focus groups interviews. Food Quality and Preference, v. 15, n. 5 , p. 477-488, 2004

\section{EMPRESA BRASILEIRA DE PESQUISA}

AGROPECUÁRIA. Disponível em: <http:// LWwW.embrapa.b-bi '> Acesso em: 20 jan. 2007.

GUERRERO, L.; COLOMER, Y.; GUÀRDIA, M. D.; XICOLA, J.; CLOTET, R. Consumer attitude towards store brands. Food Quality and Preference, v. 11, n. 5, p. 387-395, 2000.

HASHIM, I. B.; RESURREICCION, A. V. A.; McWATTERS, K. H. Consumer attitudes toward irradiated poultry. Food Technology, v. 50, n. 3, p. 77-80, 1996.

HEARTY, Á. P.; McCARTHY, S. N.; KEARNEY, J. M.; GIBNEY, M. J. Relationship between attitudes towards healthy eating and dietary behaviour, lifestyle and demographic factors in a representative sample of Irish adults. Appetite, v. 48, n. 1, p. 1-11, 2007.

INFORMATIVO CAFÉ. 2007. Disponível em: <http:// LWww.cicbr.org.bp. Acesso em: 12 fev. 2008.

JAEGER, S. R. Non-sensory factors in sensory science research. Food Quality and Preference, v. 17, n. 1/2, p. 132-144, 2006.

KAHKONEN, P.; TUORILA, H.; RITA, H. How information enhances acceptability of a low-fat spread. Food Quality and Preference, v. 7, n. 2, p. 87-94, 1996.
LAUREATI, M.; PAGLIARINI, E.; CALCINONI, O.; BIDOGLIO, M. Sensory acceptance of traditional food preparations by elderly people. Food Quality and Preference, v. 17, n. 1/2, p. 43-52, 2006.

MONTEIRO, M. A. M. Caracterização da bebida de café (Coffea arabica L.): análise descritiva quantitativa, análise tempo-intensidade e testes afetivos. 2002. $158 \mathrm{f}$. Tese (Doutorado em Ciência e Tecnologia de Alimentos) - Universidade Federal de Viçosa, Viçosa, 2002.

NGAPO, T. M.; DRANSFIELD, E.; MARTIN, J. F.; MAGNUSSON, M.; BREDAHL, L.; NUTE, G. R. Consumer perceptions: pork and pig production. Insights from France, England, Sweden and Denmark. Meat Science, v. 66, n. 1, p. 125-134, 2003.

PELCHAT, M. L. You can teach an old dog new tricks: olfaction and responses to novel foods by elderly. Appetite, v. 35, n. 2, p. 153-160, 2000.

REIS, R. C. Iogurte light sabor morango: equivalência de doçura, caracterização sensorial e impacto da embalagem na intenção de compra do consumidor. 2007. 128 f. Tese (Doutorado em Ciência e Tecnologia de Alimentos) - Universidade Federal de Viçosa, Viçosa, 2007.

SILVA, D. L. V. da; ALVES, R. E.; FIGUEIREDO, R. W. de; MACIEL, V. T.; FARIAS, J. M. de; AQUINO, A. R. L. de.Características físicas, físico-químicas e sensoriais da água de frutos de coqueiro anão verde oriundo de produção convencional e orgânica. Revista Ciência e Agrotecnologia, v.33, n.4, p.1079-1084, jul./ ago., 2009.

SOUZA, E. A. M.; MINIM, V. P. R.; CARNEIRO, J. D. S.; DANTAS, M. I. S.; RIBEIRO, M. M. O efeito da embalagem na intenção de compra do consumidor. In: ENCONTRO NACIONAL SOBRE PROCESSAMENTO MÍNIMO DE FRUTAS E HORTALIÇAS, 3., 2004, Viçosa, MG. Palestras, Resumos e Oficinas... Viçosa: UFV, 2004. p. 192.

TUORILA, H. M.; MEISELMAN, H. L.; CARDELLO, A. V.; LESHER, L. L. Effect of expectations and the definition of product category on the acceptance of unfamiliar foods. Food Quality and Preference, v. 9, n. 6, p. 421-430, 1998. 